\title{
Determining Decoupling Points in a Supply Chain Networks Using NSGA II Algorithm
}

\author{
Mina Ebrahimiarjestan ${ }^{1}$ (D), Guoxin Wang ${ }^{2}$ \\ ${ }^{1}$ Department of Industrial Engineering, Kharazmi University, Tehran (Iran) \\ ${ }^{2}$ School of Mechanical Engineering, Beijing Institute of Technology, Beijing (P.R. China) \\ ebrabimiarjestan@gmail.com,wangguoxin@,bit.edu.cn
}

Received: November 2016

Accepted: January 2017

\section{Abstract:}

Purpose: In the model, we used the concepts of Lee and Amaral (2002) and Tang and Chen (2009) and offer a multi-criteria decision-making model that identify the decoupling points to aim to minimize production costs, minimize the product delivery time to customer and maximize their satisfaction.

Design/methodology/approach: we encounter with a triple-objective model that metaheuristic method (NSGA II) is used to solve the model and to identify the Pareto optimal points. The max (min) method was used.

Findings: Our results of using NSGA II to find Pareto optimal solutions demonstrate good performance of NSGA II to extract Pareto solutions in proposed model that considers determining of decoupling point in a supply network.

Originality/value: So far, several approaches to model the future have been proposed, of course, each of them modeled a part of this concept. This concept has been considered more general in the model that defined in follow. In this model, we face with a multi-criteria decision problem that includes minimization of the production costs and product delivery time to customers as well as customer consistency maximization. 
Keywords: industrial systems, analysis points, pareto optimal points, multi-criteria decision, meta-heuristic algorithm

\section{Introduction}

Today, in complex, dynamic and highly variable environments companies need to design and choose strategies that can help them to improve their growing performance because in such a competitive environment the companies can survive that compete with the others and adjust to the dynamic and changing conditions of the competitive market (Aitken, 2000). On the other hand, supply the right product at reasonable price to the consumer at the right time is not the only condition to success a competition but also is the key to its survival. The Supply chain performance initiatives are trying to match supply to demand and thus reduce costs while improving customer satisfaction. Today, providing the best performance in the field of marketing has become the primary concern of corporate executives and try taking advantage of different fans achieve superior performance. According to Cooper, superior performance is dependent on the ability of a manufacturer in full-scale integration with our partners throughout the supply chain (Christopher \& Towill, 2001). Therefore, regarding the changes in organization and manufacturing management and improving productivity, numerous tools and techniques developed and employed. Lean thinking is considered one of the most important of them refers the organization that ends the process up without wasting resources or spending less four resources increase more production (Christopher, 2000). Agile technique is one of supply chain technique that follows flexibility and focuses on the unpredictable change in markets and benefits of them by fast delivery and flexibility on the size and type of product. Therefore, lean and agile models are considered in many companies that are looking to improve their performance (Mottaghi, 2004). Therefore, the "strategy" should be chosen aware of these contradictions and the necessity of choosing between competitive criteria such as speed, efficiency, quality, cost, and satisfaction and so on or mixed modes and the supply chain need to adopt a strategy that suits for both types of their production, that is, "special and marketinteresting". 


\section{Literature Review}

\subsection{Separation Point}

Decoupling points in a supply chain network are areas that break down the production line to lean manufacturing system and agile manufacturing system. Lean manufacturing is based on the strategy of make to stock (MTS). In MTS, products are stored in the warehouse until they create demand for products. Then the products are delivered from the warehouse to the customer, and the good delivery to the customer is as a pulse for the last station on the assembly line. There is a pulse to produce the station from beginning the process in each station to the output from the previous station. In lean manufacturing, it is clear that the goods or services that delivered to the customer are based on the standard characteristics, and the specific feature of the customer is not considered. The advantage of this strategy is that the product delivery time to the customer is at its minimum level. Such a mechanism is shown in Figure 1.

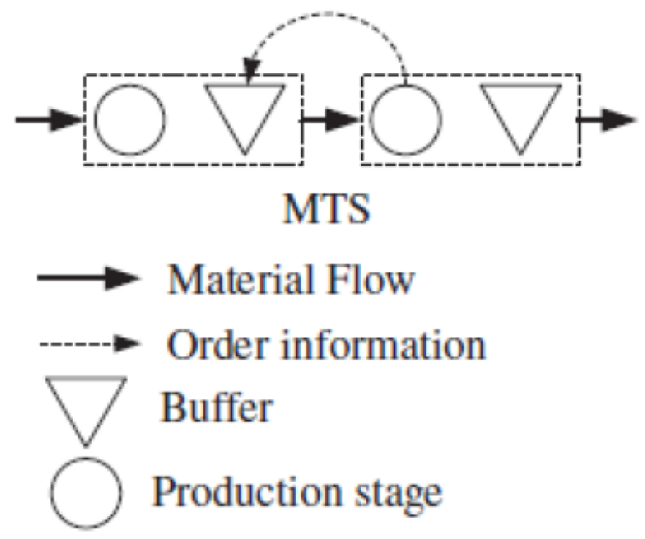

Figure 1. Make to storage (lean manufacturing)

On the other hand, agile manufacturing systems are based on the make to order (MTO) strategy and customer demand is provided for the full terms of the given characteristics. In this system, when a custom station receives an order, the product is produced according to the requested specifications. In this case, the customer satisfaction from the product is at its highest level. However, the delivery time to customers is at its maximum, since it involves all stages of production, as well as product design modification. The changes in production and design lead to high production costs, and it is clear that a company that adopts this strategy should have the competencies and competitive advantages including flexibility, professional expert and so on. An example of this strategy is shown in Figure 2. 


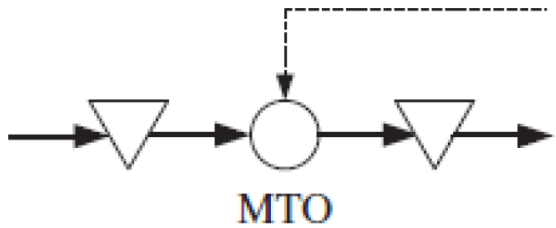

Figure 2. make to order (agile technology)

According to the above description, each strategy has advantages and disadvantages. So a good strategy can use the advantages of both. The concept is expressed using decoupling points in a supply chain network. So a supply network can be decomposed into two parts, the upstream and downstream sectors. The upstream section includes manufacturing operations from the beginning of the production process to decoupling points and downstream is from break point until the end of production lines. MTS and MTO strategies are used in the upstream and downstream sectors respectively. In literature, MTS and MTO are presented with the other titles like compressive and tensile strategies.

To identify decoupling points, three important aspects should be considered:

1. Minimization of the production cost

2. Minimization of the delivery time to the customer

3. Maximization of the customer satisfaction.

So we faced with a multi-objective problem.

For this purpose we use the supply chain network that has been proposed by Sun, Ji, Sun and Wang (2008). Here we have multiple decoupling points on the line that divides network nodes into two parts. In this network, the prerequisite relationships between the various activities in the manufacturing process of a product are shown, and the presentation of the activities for the production of a product is more convenient to calculate the time of delivery to the customer. Such a network is shown in Figure 3 (Sun et al., 2008). 


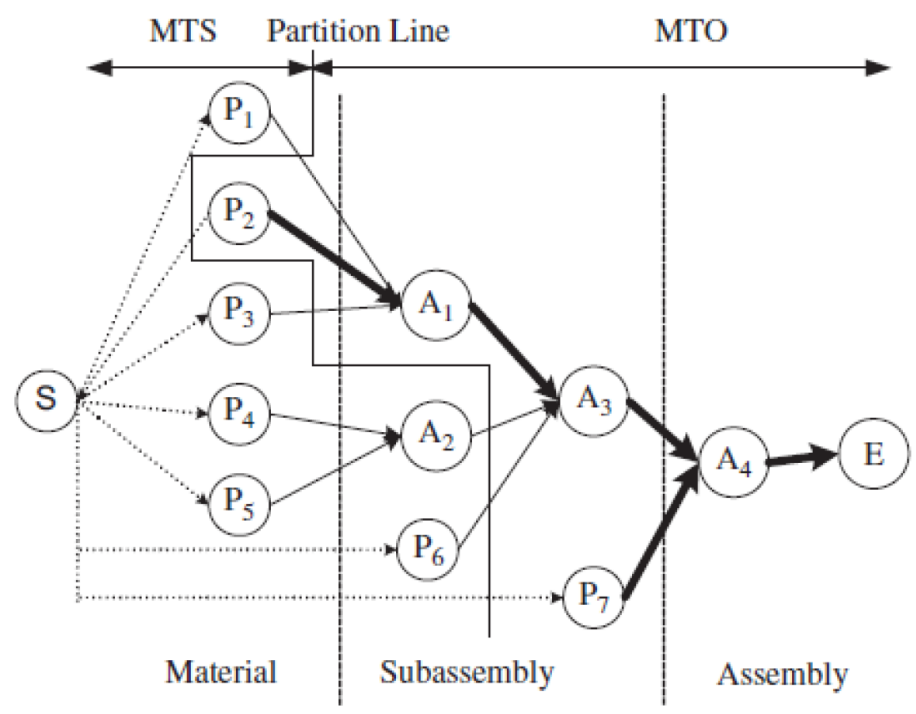

Figure 3. The supply product chain (Sun et al., 2008)

In Figure 5, the nodes show products. Here, the required raw materials are shown by Pi and semi-finished products during the manufacturing process and the final product will are shown by Ai. In the model, we used the concepts of Lee and Amaral (2002) and Tang and Chen (2009) and offer a multi-criteria decision-making model that identify the decoupling points to aim to minimize production costs, minimize the product delivery time to customer and maximize their satisfaction.

The way to solve the problem and choosing the MTO and MTS is a meta-heuristic Algorithm that chooses only the optimal points of Pareto. Finally, with delivery of these points to the management, he is responsible to make the final decision from these points.

The effect of information technology on the supply chain agility and companies' performance have been investigated by (DeGroote \& Marx, 2013). The ability of perception criteria and response to market change have been suggested as supply chain agility. To this end, required information have gathered from supply chain manager of 219 American company, then analyzed. Results showed that information technology can improve the ability of supply chain in market change perception by enhancing adequacy, accuracy, availability and Timeliness of information flow among supply chain members. In addition, increasing the supply chain agility induces positive effects on sales, market share, profitability and customers' satisfaction of the investigated companies. Agarwal, Shankar and Tiwari (2007) have modelled the supply chain agility. They have recognized 4 important aspect in an agile supply chain, then evaluate them in under investigated organization. These four aspect are processes, planning, market and information (Agarwal et al., 2007). 
Agarwal, Shankar and Tiwari (2006) have presented a network analysis process-based framework in order to modelling the performance measurement of three strategies in supply chain (Lean, Agile, Lean/Agile). The main aim of this studies was the performance evaluation and the selection of most appropriate strategy in order to enhancing the supply chain performance. Additionally, cost, quality, service level and waiting time were the four major criteria in supply chain factor analysis. These investigations showed the lean/agile is the most appropriate strategy for improving supply chain performance. This results also shows the tendency of managers in order to runs policies for combining the lean and agile approaches in supply chain (Agarwal et al., 2006).

Krishnamorti and Yauch (2007) have studied the implementing capability of lean/agile fabrication strategy in manufacturing company which has several business units. They results showed that the agile and lean fabrication are the supportive strategies and manufacturing companies can use these strategies, simultaneously. Moreover, a theoretical infrastructure for lean/agile model in which lean and agile strategies are acting in different part of the company and are separated by a breakpoint have presented. The proposed infrastructure is made of decentralized organizational structure with small and medium-sized for agility, and the centralized organizational structure with large and medium-sized for leanness (Krishnamurthy \& Yauch, 2007).

Regarding to the discussed features, lean supply chain cannot meet the customer needs, quickly. Therefore, lean/agile supply chain which combines the benefits of lean and agile supply chain have been recommended. In fact, lean/agile supply chain with combining lean and agile strategies provides rapid response to changing demands of upstream and downstream companies with maintaining and consolidating its own position in the supply chain Cao and Zhang (2011). Based on the major goal of the supply chain, customer satisfaction, Naim and Gosling (2011), quoting Johnson, have defined four criterion as a main criterion for comparing lean and agile supply chain. These criteria are services, quality, cost and waiting time which agility and leanness value of supply chain are depend on the size of them (Gosling, Purvis, L., Naim, 2010).

Perez, Castro, Simons and Gimenez (2010) have analyzed the performance and features of Catalan meat supply chain with the aim of whether those responsible for lean supply chain is used in the industry. In this regard, a conceptual model have used as an evaluation tool. (Perez et al., 2010).

Our exploration on the implication of the CODP on the modelling of value is based on the differences between the distinguishing features for value chain operations upstream the decoupling point (i.e. towards the supplier) versus those downstream the decoupling point (i.e. towards the ultimate customer) and impact of having the decoupling point at different positions which have studied by (Olhager, 2012). 
Based on a review of the 'leagile' literature, Nieuwenhuis and Katsifou (2015) shows that a new understanding of the factors that determine the 'decoupling point' between lean and agile processes can be used in order to bring about a radical shift in economies of scale in car production. In this way, lower volume production becomes feasible thereby reducing the need for overproduction and enabling a move towards more sustainable car production and hence consumption. By way of illustration, you should consider how Morgan Motor Company implement such an approach in practice (Nieuwenhuis \& Katsifou, 2015).

\section{Modeling of the Problem}

\subsection{Decision Variable}

Decision variable in this model is to produce every product with the strategy of MTO or MTS, hence the decision variables is considered as $O_{i}$ in follows:

$$
O_{i}= \begin{cases}1 & \text { if product i is MTObased } \\ 0 & \text { else }\end{cases}
$$

\subsection{Delivery Time}

The arcs of the network between every of two nodes indicates the processes to convert the two products in both nodes is done. These activities include manufacturing processes and assembly products. Each arc includes a time (uptime) and so the delivery time of product is as long as the root node to the end node, and so is equal to the critical time of the network. So if activities on the network were shown with MTO and MTS, as mentioned above, the MTS activities have the least amount of possible delivery time and therefore the time of the activities in the delivery to client is considered negligible and zero. Also, for the activities that are produced as MTO, The total time of product in different workstations is the time of delivery to the customer. So to extract the time of delivery to the customer from the network, all the directions from the beginning node to the end one are consider. Time activities of MTO on the every track are sum up is that the delivery time of goods from the track to the customer. The longest of these times is the delivery time of goods to the customer. So delivery time of goods to customers $T$ can be obtained from the following equation:

$$
T_{\text {path }}=\sum_{i \in \text { path }} D_{i} \cdot T_{i} \cdot O_{i}
$$

$T \geq T_{\text {path }} \quad$ for all paths from root node toleaf node 


\subsection{The Fee Structure}

In problem modeling, regarding that the decision variable means every production activity to be produced by MTS or MTO, we determine the cost structure considering this variable in which there is the meaningful effect in present of MTS and MTO. In other words, the only costs are considered when MTS and MTO are chosen. For examples, the cost that is common in both strategies is neglected, and the only cost that differs in MTS and MTO $i$ considered. In MTS strategy activities, production is based on prediction and the product is provided in standard terms, not the ordered and then there is no need to modification of production structure and product design. Noted, in MTS the products stored in the warehouse, the cost of storage is one of the main components of cost, and as we know in MTO because the product is produced strictly according to demand, there is no cost like this. Another cost structures that differ between MTO and MTS is the cost preparation. The one for MTO is relatively high because these costs are considered for each of the products that are produced. In MTS, the products are produced as batch production, so these costs are limited only to the category of the production.

At MTO also, there a cost of customizing that can be considered as costs of production adjustment and design. In this study, we assume that the order is constant that is shown by $D$ in the planning horizon. To obtain the demand for intermediate products, we use the bills of materials (BOM) and perquisite relationships of the network. The materials bill is shown by BOM matrix in which BOM ( $i$, j) represents the number of products from $i$ that is required to produce a unit of product of $j$. So if the demand for product $j$ is shown by $D_{j}$, the product demands for $i$ is obtained by the following equation:

$$
D_{i}=\sum_{j \in \text { product }, j \neq i} B O M(i, j) \cdot D_{j}
$$

We assume a constant rate of production of each product. Also in the modeling notations we have:

$S_{i:}$ preparation cost for product $i$

$H_{i}$ : The cost of maintenance for each unit of product $j$ in a year

$u_{i}:$ production rate

$p_{i}$ : demand rate

We also assume that at MTS strategy production, there is no shortage of licensed products. Otherwise, the assumption of MTS product delivery time will be zero is contravened. So we know that this model is a model of economic production quantity (EPQ) and know the total cost including the cost of preparing and maintains in EPQ model is obtained as follows: 


$$
T C_{i}^{*}=\sqrt{2 D_{i} S_{i} H_{i}\left(1-\frac{u_{i}}{p_{i}}\right)}
$$

On the other hand, if we consider the activity as MTO, the cost of preparing a must for all demands will be addressed in other words the cost of preparation. As well as the cost of customization for all applications also assume that if the price customizing of the product $i$ is $C S_{i}$, the cost will be equal to customizing the product $i$. So for product $i$ that the MTO is produced, the cost will be as follows:

$$
T C_{i}=S_{i} D_{i}+C S_{i} D_{i}
$$

\subsection{Customer Satisfaction}

As noted, one of the goals of our model is to maximize customer satisfaction. Maximizing customer satisfaction ensures future demand of products and company profit in development outlook. In this model, we assume that if the product to be produced as standard (strategy MST), customer satisfaction is the product $S F_{i}$ and if the product is customized production (strategy MTO) customer satisfaction is $C F_{i}$. $C F_{i}$ is larger than $S F_{i} . C F_{i}$ and $S F_{i}$ values can be calculated using value analysis and qualitative studies such as analysis factor; however, in this case, we assume that this information is already known. So the customer satisfaction of product i can be expressed as follows.

\subsection{Prerequisites Restrictions}

Prerequisite is defined because if product $i$ was produced with MTO manufacturing strategy, all products that are related to this product, in another word the product $i$ is their prerequisite product before they need to be produced with MTO strategy. This restriction has, in fact, the concept of decomposition point that divides production line and supply chain network into two parts of upstream and downstream. Hence, these restrictions should also be added to the model.

With the above explanation, the supply network planning model can be characterized as follows: 


$$
\begin{array}{ll}
\min & \sum_{i \in \text { product }}\left(\left(S_{i} D_{i}+C S_{i} D_{i}\right) \cdot O_{i}+\left(1-O_{i}\right) \cdot \sqrt{2 D_{i} S_{i} H_{i}\left(1-\frac{u_{i}}{p_{i}}\right)}\right. \\
\max & \sum_{i \in \text { product }}\left(O_{i} \cdot c f_{i}+\left(1-O_{i}\right) \cdot S f_{i}\right) \\
\min \quad & T \\
\text { s.t }: & \\
& T_{\text {path }}=\sum_{i \in \text { path }} T_{i} \cdot O_{i} \\
& T \geq T_{\text {path }} \quad \text { for all paths } \\
& O_{i} \geq O_{j} \quad \text { for all iand } j \text { such that } j \in \text { all path rooted from } i \\
& O_{i}=\{0,1\}
\end{array}
$$

\section{The Proposed Solution Method}

\subsection{NSGA II Algorithm}

Non-Dominated Sorting Genetic Algorithm (NSGA-II), a popularly used algorithm proposed by Deb, Pratap, Agarwal and Meyarivan (2002) offers a great approach to deal with multi-objective optimization problem. This algorithm has some improvement over the original one (Srinivas \& Deb, 1995). In this section, we describe this algorithm briefly. Details can be found in Deb (2001). In NSGA-II, firstly the offspring population $Q_{t}$ is formed from the parent population $P_{t}$. The combination of two populations is $R_{t}$ of size $2 N$. Then a non-dominated sorting classifies the entire population $R_{t}$. This process will allow a global non-domination check among the offspring and parent solutions (Deb, 2001). Two most important concepts in NSGA-II are a fast non-dominated sorting of the solutions population and a crowding distance calculation.

Crowding distance calculation: This procedure is used as an estimation of solutions near a particular solution in the population. Firstly sorting the population is done according to each objective function value in their ascending order of extent. Then the limit solutions (solutions with smallest and largest functions values) for each objective function are assigned an infinite distance value. All other solutions between boundary solutions are assigned a distance value equal to the absolute difference in the function values of two adjacent solutions. This calculation is done for all the objective functions. The overall crowding distance is calculated as the sum of individual distance values corresponding to each objective. This procedure is as follow (Deb, 2001): 
crowding-distance-assignment $(\mathcal{I})$

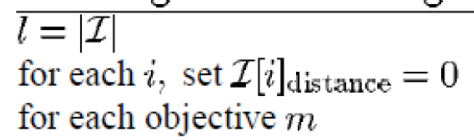

for each objective $m$

$$
\begin{array}{ll}
\mathcal{I}=\operatorname{sort}(\mathcal{I}, m) & \text { sort using each objective value } \\
\mathcal{I}[1]_{\text {distance }}=\mathcal{I}[l]_{\text {distance }}=\infty & \text { so that boundary points are always selected } \\
\text { for } i=2 \text { to }(l-1) & \text { for all other points } \\
\mathcal{I}[i]_{\text {distance }}=\mathcal{I}[i]_{\text {distance }}+(\mathcal{I}[i+1] \cdot m-\mathcal{I}[i-1] . m) /\left(f_{m}^{\max }-f_{m}^{\min }\right)
\end{array}
$$

number of solutions in $\mathcal{I}$

initialize distance

Fast non-dominated sorting: Here we form a non-dominated set of solution. The first solution from the set is kept in a set $P$. Then, each subsequent solution is compared with all members of the set $P$. If the solution $q$ is dominated by $p$, then solution $q$ is removed from $P$. Thus, these dominated solutions get eliminated from $P$. Otherwise, if any member of $P$ dominates the solution $p, p$ is disregarded. The solution $p$ entered in $P$ if it is not dominated by any member of $P$. After that all check is done, the solution set $P$, considered as a non-dominated set. The procedure is as follow (Deb, 2001):

Fast- non-dominated-sort $(P)$

For each $p \in P$

$S_{p}=\varnothing$

$n_{p}=0$

For each $q \in P$

if $(p<q)$ then

$$
S_{p}=S_{p} \cup\{q\}
$$

else $(q<p)$ then

$$
\begin{gathered}
n_{p}=n_{p}+1 \\
\text { if } \begin{array}{c}
n_{p}=0 \text { then } \\
P_{\text {rank }}=1 \\
f_{1}=f_{1} \cup\{p\}
\end{array}
\end{gathered}
$$

$$
i=1
$$

while $f_{i} \neq \varnothing$

$$
Q=\varnothing
$$

for each $p \in f_{i}$

for each $q \in s_{p}$

$$
\begin{gathered}
n_{q}=n_{q}-1 \\
\text { if } n_{q}=0 \text { then } \\
q_{\text {rank }}=i+1 \\
Q=Q \cup\{q\}
\end{gathered}
$$

$i=i+1$

$F_{i}=Q$

In NSGA II algorithm, firstly a random population, $P_{0}$, of size $N$ is created. The population is sorted into different non-domination levels, with the best level as 1 (i.e. sorting will result in different non-dominated fronts, and the best non-dominated front is called level 1) considering minimization of fitness. Binary 
tournament selection, recombination, and mutation operators are executed to generate the population of the following generation, $Q_{0}$, of size $N$. The procedure (Figure 4), for the remaining generation (for $t \geq 1$ ) is as follows (AL-Fayyaz, 2004):

Step 1. First a combined population (parent and offspring) of size $2 N, R_{t}=P_{t} \cup Q_{t}$ is formed, which is sorted according to a fast non-domination procedure. This step results in different non-dominated fronts $F_{1}, F_{2}$, etc.

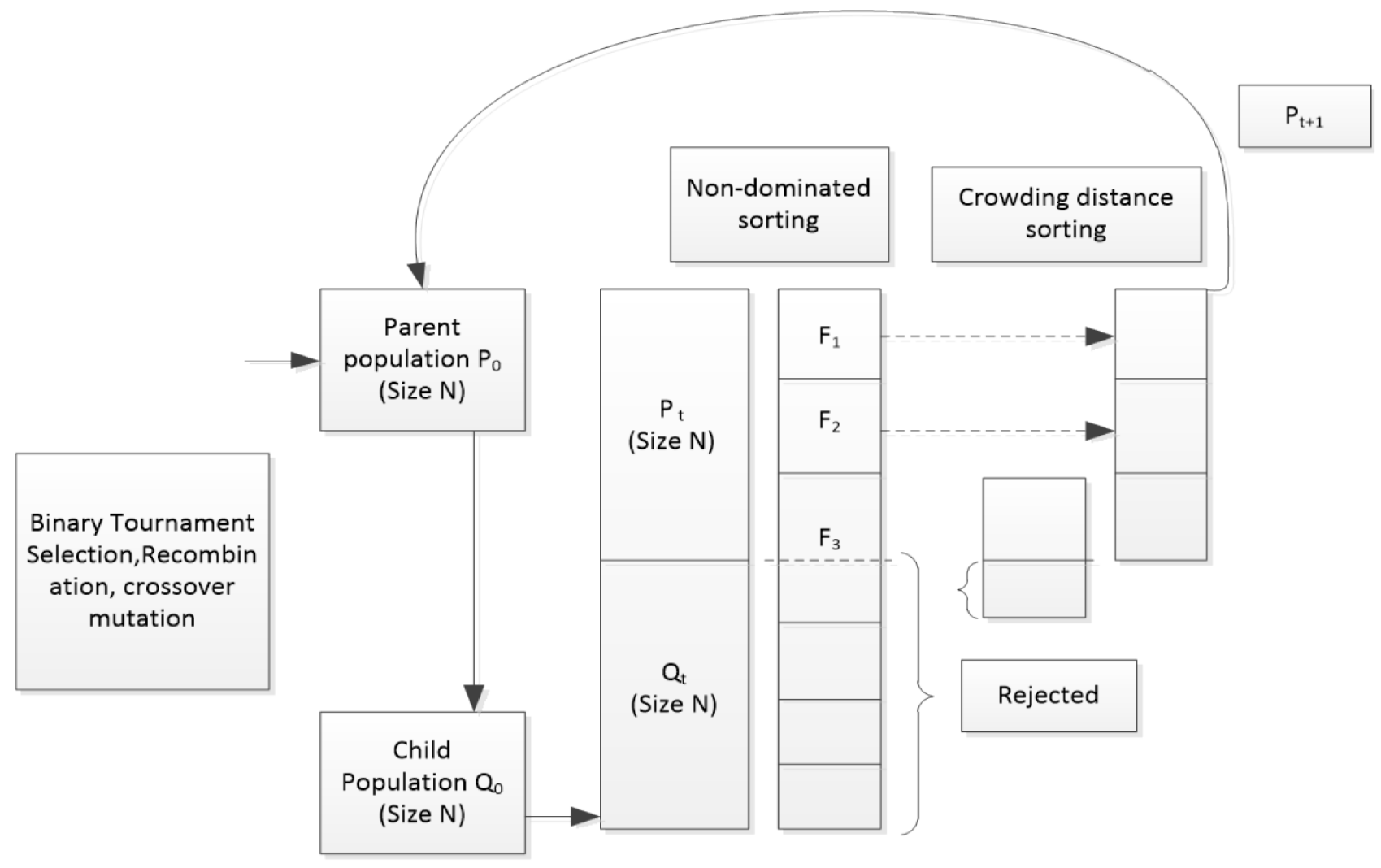

Figure 4. Graphical diagram of NSGA-II Algorithm (Deb, 2001)

Step 2. The new parent population $P_{t+1}$ is formed by adding solutions from the first front $F_{1}$ and continuing till the size exceeds $N$;

Step 3. The solutions of the last accepted front are sorted according to a crowded comparison criterion (to maintain diversity in the population, this criterion is used which prefers a point that is located in a region with lesser number of points) and a total of $N$ points are picked;

Step 4. The population $P_{t+1}$ of size $N$ is constructed in which selection, crossover, and mutation are used to create the new population $Q_{t+1}$ of size $N$. This procedure is repeated for other following generations. It 
is important to mention here that the non-dominated sorting in step 1 and filling up population $P_{t+1}$ can be performed together. In each time a non-dominated front is found, its size can be checked whether it can be included in the new population. If not, then no more sorting is needed. This will reduce the run time of the algorithm.

\subsection{Numerical Examples}

Consider following supply chain network shown in Figure 5:

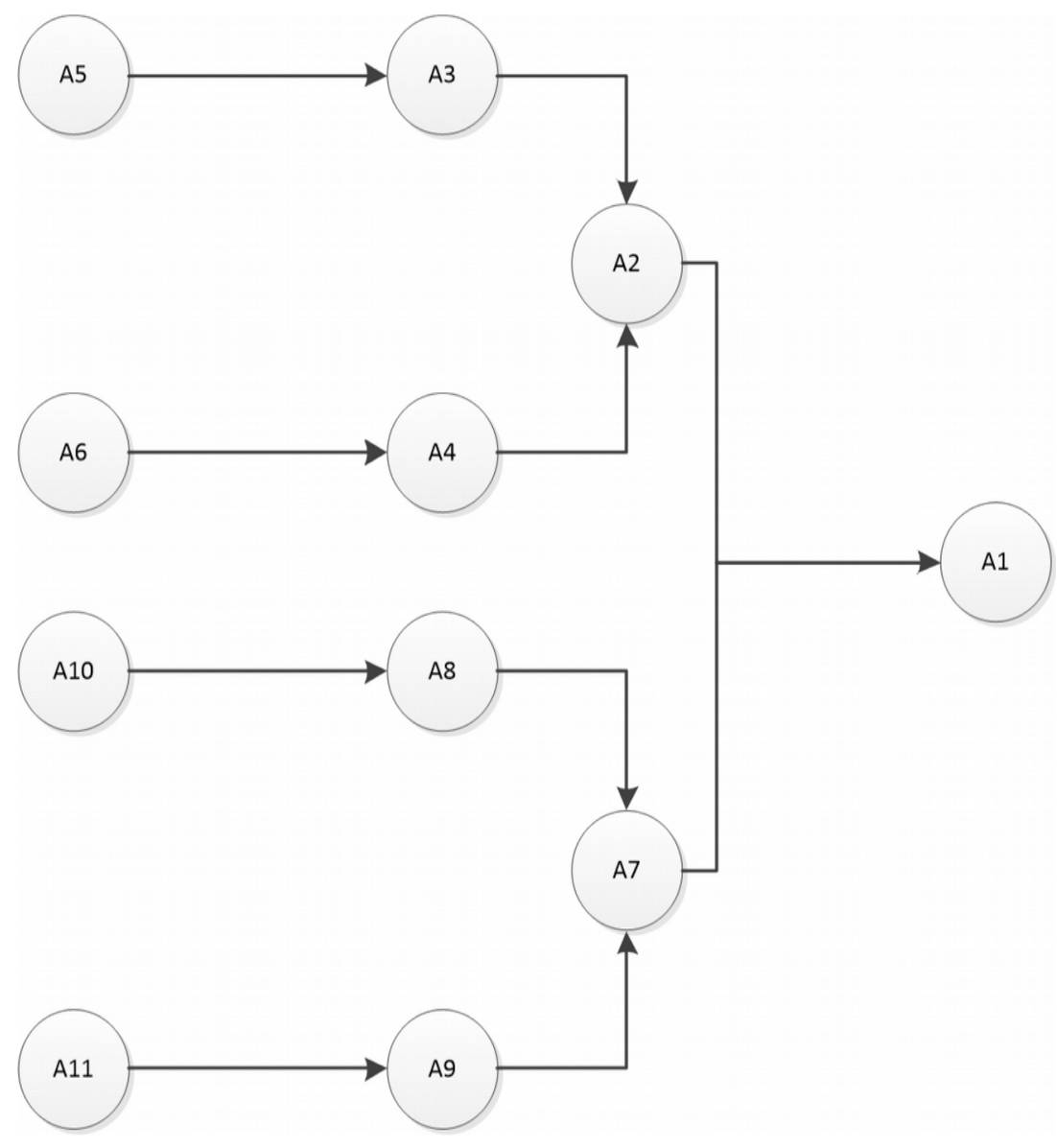

Figure 5. supply chain network example

We use a string that contains 11 bit to represent a solution of this model. Each bit takes value 0, if corresponding operation be MTO and 1 otherwise. For example the representation D1 shows the solution that operations A1, A2 and A7 are MTO operation and other operations are MTS; in other words operations A2 and A7 act as decoupling points:

D1: $\left[\begin{array}{lllllllllll}1 & 1 & 0 & 0 & 0 & 0 & 1 & 0 & 0 & 0 & 0\end{array}\right]$ 
This network has parameters as below:

$$
\begin{aligned}
& C S=\left[\begin{array}{lllllllllll}
10 & 9 & 7 & 8 & 6 & 6 & 9 & 8 & 7 & 8 & 9
\end{array}\right] ; \\
& T=\left[\begin{array}{lllllllllll}
6 & 6 & 6 & 6 & 1 & 8 & 10 & 4 & 10 & 4 & 9
\end{array}\right] ; \\
& S=\left[\begin{array}{lllllllllll}
2 & 2 & 1 & 1 & 2 & 3 & 4 & 3 & 1 & 4 & 4
\end{array}\right] ; \\
& H=\left[\begin{array}{lllllllllll}
0.77 & 0.04 & 0.37 & 0.70 & 0.72 & 0.22 & 0.27 & 0.67 & 0.47 & 0.62 & 0.24
\end{array}\right] ; \\
& s f=\left[\begin{array}{lllllllllll}
0.18 & 0.83 & 0.76 & 0.93 & 0.11 & 0.18 & 0.1 & 0.49 & 0.19 & 0.89 & 0.1
\end{array}\right] ; \\
& c f=\left[\begin{array}{lllllllllll}
0.35 & 1.66 & 1.53 & 1.87 & 0.21 & 0.36 & 0.2 & 0.97 & 0.38 & 1.79 & 0.19
\end{array}\right] ; \\
& p=\left[\begin{array}{lllllllllll}
5 & 8 & 9 & 6 & 6 & 7 & 6 & 8 & 10 & 8 & 5
\end{array}\right] ; \\
& d=69 ; \\
& u=\left[\begin{array}{lllllllllll}
4.0 & 6.4 & 7.2 & 4.8 & 4.8 & 5.6 & 4.8 & 6.4 & 8.0 & 6.4 & 4.0
\end{array}\right] ;
\end{aligned}
$$

Here, element $i$ of each vector, corresponds to related vector parameter of operation $i$.

Also, each solution like $D 1$ is labeled with a matrix that shows the value of operations in the solution corresponding to all routs that originate from the final product (in this example A1) and terminate to network leaves (here A5, A6, A10 and A11). This matrix is useful when we want to compute final product delivery time and use crossover operation in NSGA II to generate new solutions. In the network in Figure 5, there are four routs that are A1-A2-A3-A5, A1-A2-A4-A6, A1-A7-A8-A10, and A1-A7-A9-A1. In the labeled matrix for each rout, we have a row that has $\underline{n}$ elements ( $n$ is equal to the number of all operations). The element of labeled matrix is defined as follow:

$$
S(i, j)=\left\{\begin{array}{ll}
1 & \text { if operation } j \text { is on rout iand is MTO operation } \\
0 & \text { else }
\end{array}\right\}
$$

For example labeled matrix of solution D1 is as follow:

$$
S 1=\left[\begin{array}{lllllllllll}
1 & 1 & 0 & 0 & 0 & 0 & 0 & 0 & 0 & 0 & 0 \\
1 & 1 & 0 & 0 & 0 & 0 & 0 & 0 & 0 & 0 & 0 \\
1 & 0 & 0 & 0 & 0 & 0 & 1 & 0 & 0 & 0 & 0 \\
1 & 0 & 0 & 0 & 0 & 0 & 1 & 0 & 0 & 0 & 0
\end{array}\right]
$$

As mentioned in section 3, each operation has a time (the vector $T$ shows time of each operation) and if that operation is considered as MTO, affects delivery time in constraint (3) and (4). Now we can easily compute final product delivery time as follow:

$$
\text { Delivery time }=\min S(i,:) T^{\prime}
$$


$S(i,:): i$ 'th row of matrix $S$

In the network of Figure 4, there are 35 combinations of MTO and MTS operations; therefore we have 35 solutions which must be considered. Matrix D shows all 35 representations.

$D=\left[\begin{array}{lllllllllll}1 & 1 & 1 & 1 & 1 & 1 & 1 & 1 & 1 & 1 & 1 \\ 0 & 1 & 1 & 1 & 1 & 1 & 0 & 0 & 0 & 0 & 0 \\ 0 & 0 & 1 & 1 & 1 & 1 & 1 & 1 & 1 & 1 & 1 \\ 0 & 1 & 1 & 1 & 1 & 1 & 0 & 1 & 1 & 1 & 1 \\ 0 & 0 & 1 & 1 & 1 & 1 & 0 & 1 & 1 & 1 & 1 \\ 0 & 0 & 0 & 1 & 1 & 1 & 1 & 1 & 1 & 1 & 1 \\ 0 & 0 & 1 & 0 & 1 & 1 & 1 & 1 & 1 & 1 & 1 \\ 0 & 1 & 1 & 1 & 1 & 1 & 0 & 0 & 1 & 1 & 1 \\ 0 & 1 & 1 & 1 & 1 & 1 & 0 & 1 & 0 & 1 & 1 \\ 0 & 0 & 0 & 0 & 1 & 1 & 1 & 1 & 1 & 1 & 1 \\ 0 & 0 & 0 & 1 & 1 & 1 & 0 & 0 & 1 & 0 & 0 \\ 0 & 0 & 0 & 1 & 1 & 1 & 0 & 1 & 0 & 1 & 1 \\ 0 & 0 & 1 & 0 & 1 & 1 & 0 & 0 & 1 & 1 & 1 \\ 0 & 0 & 1 & 0 & 1 & 1 & 0 & 1 & 0 & 1 & 1 \\ 0 & 1 & 1 & 1 & 1 & 1 & 0 & 0 & 0 & 1 & 1 \\ 0 & 0 & 0 & 0 & 1 & 1 & 0 & 0 & 1 & 1 & 1 \\ 0 & 0 & 0 & 0 & 1 & 1 & 0 & 1 & 0 & 1 & 1 \\ 0 & 0 & 0 & 1 & 1 & 1 & 0 & 0 & 0 & 1 & 1 \\ 0 & 0 & 1 & 0 & 1 & 1 & 0 & 0 & 0 & 1 & 1 \\ 0 & 0 & 0 & 0 & 1 & 1 & 0 & 0 & 0 & 1 & 1 \\ 0 & 0 & 0 & 1 & 0 & 1 & 1 & 1 & 1 & 1 & 1 \\ 0 & 0 & 1 & 0 & 1 & 0 & 1 & 1 & 1 & 1 & 1 \\ 0 & 1 & 1 & 1 & 1 & 1 & 0 & 0 & 1 & 0 & 1 \\ 0 & 1 & 1 & 1 & 1 & 1 & 0 & 1 & 0 & 1 & 0 \\ 0 & 0 & 0 & 0 & 0 & 0 & 1 & 1 & 1 & 1 & 1 \\ 0 & 0 & 0 & 1 & 0 & 1 & 0 & 0 & 1 & 0 & 1 \\ 0 & 0 & 0 & 1 & 0 & 1 & 0 & 1 & 0 & 1 & 0 \\ 0 & 0 & 1 & 0 & 1 & 0 & 0 & 0 & 1 & 0 & 1 \\ 0 & 0 & 1 & 0 & 1 & 0 & 0 & 1 & 0 & 1 & 0 \\ 0 & 1 & 1 & 1 & 1 & 1 & 0 & 0 & 0 & 0 & 0 \\ 0 & 0 & 0 & 0 & 0 & 0 & 0 & 0 & 1 & 0 & 1 \\ 0 & 0 & 0 & 0 & 0 & 0 & 0 & 1 & 0 & 1 & 0 \\ 0 & 0 & 0 & 1 & 0 & 1 & 0 & 0 & 0 & 0 & 0 \\ 0 & 0 & 1 & 0 & 1 & 0 & 0 & 0 & 0 & 0 & 0 \\ 0 & 0 & 0 & 0 & 0 & 0 & 0 & 0 & 0 & 0 & 0 \\ & & & & & & & & & & \end{array}\right]$

In Table 1, which $\mathrm{D}_{\mathrm{i}}$ corresponds to solution $i$, the objective functions regarding each solution are shown in the descending order as we have expected there is some conflict between model objectives For example, while solution D1 has maximum utility considering cost, it has minimum customer satisfaction. For above example we have all Pareto optimal solutions as below:

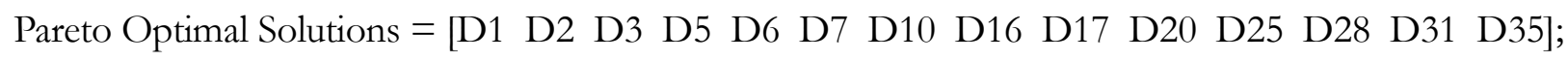

To validate NSGA II algorithm for solving this problem, we mention some properties of NSGA II again. We use all procedure of NSGA II that was described in section 2, but to customize NSGA II, for proposed model we must define following procedure: 
- Adjust solution D:

- When making a new solution, if an operation is considered as MTO, all operations that originated from that operation and terminated at final operation are also considered MTO.

- When making a new solution, if an operation is considered as MTS, all operations that originated from that operation and terminated at final leaves also is considered MTS.

- Initialization:

- Generate K initial solution

$$
\begin{aligned}
& \text { For } i=1 \text { to } k \\
& \begin{aligned}
\text {-select } p 1 \text { randomly between } 0 \text { and } 1 \\
\text {-select } p 2 \text { randomly between } 0 \text { and } 1 \\
\text {-if } p 1<0.5 \\
-j 1=\text { random number between } 1 \text { to } 6 \\
-D_{i}(j 1)=1 ; \\
- \text { adjust } D_{i} \\
\text {-if } p 2<0.5 \\
\quad-j 2=\text { random number between } 7 \text { to } 11 \\
-D_{i}(j 2)=1 ; \\
- \text { adjust } D_{i}
\end{aligned}
\end{aligned}
$$

- Crossover:

-assume $D_{i}$ is corresponding to parent 1 with labeled matrix $S_{i}$, and $D_{j}$ is corresponding to parent 2 with labeled matrix $S_{j}$

-select one row of $S_{i}$ randomly

-select one row of $S_{j}$ randomly

-exchange two random rows, between $S_{i}$ and $S_{j}$

-generate two new solutions based on new $S_{i}$ and $S_{j}$

- Mutation:

-select $q 1$ randomly between 0 and 1

-if $q 1<0.1$

-Select one operation randomly and changed its corresponding value

In the current solution. For example, if its value is 1 , change it to 0 and if

Its value is 0 change it to 1 .

-adjust mutated solution. 


\begin{tabular}{|c|c|c|}
\hline Cost & -Satisfaction & Time \\
\hline D1(731.64) & D35(-9.55) & $\mathrm{D} 1(0)$ \\
\hline D3(2218.2) & D31(-9.25) & $\mathrm{D} 2(6)$ \\
\hline D4(2295.0) & D34(-8.67) & D3(12) \\
\hline D6(2746.8) & D33(-8.43) & D5(12) \\
\hline D7(2795.7) & D28(-8.38) & D4(16) \\
\hline D9(2817.5) & D20(-8.26) & D6(18) \\
\hline D8(2929.4) & D32(-8.16) & D7(18) \\
\hline D5(3048.7) & D26(-8.14) & D10(18) \\
\hline D21(3208.8) & D11(-8.13) & D11(18) \\
\hline D10(3324.4) & D16(-8.07) & D12(18) \\
\hline D22(3375.2) & D17(-7.77) & D13(18) \\
\hline D15(3451.9) & D25(-7.77) & D14(18) \\
\hline D23(3603.4) & D19(-7.49) & D16(18) \\
\hline D24(3656.2) & D10(-7.48) & D17(18) \\
\hline D12(4099.9) & D18(-7.33) & D18(18) \\
\hline D14(4148.8) & D13(-7.30) & D19(18) \\
\hline D13(4260.7) & D29(-7.29) & D20(18) \\
\hline D25(4365.8) & D27(-7.04) & D21(19) \\
\hline D17(4677.5) & D14(-7.00) & D25(19) \\
\hline D18(4734.3) & D22(-6.89) & D26(19) \\
\hline D19(4783.2) & D12(-6.84) & D27(19) \\
\hline D16(4789.3) & $\mathrm{D} 2(-6.72)$ & D31(19) \\
\hline D2(4964.6) & D30(-6.72) & D32(19) \\
\hline D30(4964.6) & D7(-6.71) & D33(19) \\
\hline D20(5311.9) & D21(-6.65) & D35(19) \\
\hline D26(5347.8) & D6(-6.54) & D8(20) \\
\hline $\mathrm{D} 27(5400.5)$ & D23(-6.43) & $\mathrm{D} 15(20)$ \\
\hline D28(5514.2) & D5(-5.88) & D23(24) \\
\hline $\mathrm{D} 29(5566.9)$ & D3(-5.78) & D28(24) \\
\hline $\mathrm{D} 11(5724.5)$ & D15(-5.73) & D30(24) \\
\hline D31(6504.8) & D8(-5.54) & D34(24) \\
\hline D32(6557.5) & D24(-5.34) & $\mathrm{D} 9(26)$ \\
\hline D33(6708.9) & $\mathrm{D} 9(-5.24)$ & $\mathrm{D} 22(26)$ \\
\hline D34(6875.3) & D4(-5.05) & $\mathrm{D} 29(26)$ \\
\hline D35(7866) & D1(-4.77) & D24(35) \\
\hline
\end{tabular}

Table 1. Priority of solution regarding each objective 
In this example we set initial size of population equal to 8 , therefore in each iteration we must consider a population of size 16. Using this algorithm we have final Pareto solutions as follow:

D16, D5, D1, D28, D35, D6, D17, D25, D31;

We now face with problem of choosing solution among Pareto optimal solutions. In fact the answer is based on managerial consideration. Nonetheless we can find some suggestions in literature to cope with this problem. For example we can use following methods:

- Max-min:

$$
\begin{aligned}
& \max \left\{\min _{k}\left\{f_{1, k}, f_{2, k}, \ldots, f_{N_{p}, k}\right\}\right\} \\
& k=1,2, \ldots, N_{k} \text { : set of pareto solution } \\
& i=1,2, \ldots, N_{p} \text { : set of objective function }
\end{aligned}
$$

- Normalized membership ranking:

$$
\begin{gathered}
\mu_{i}^{k}=\frac{f_{i}^{\max }-f_{i}^{k}}{f_{i}^{\max }-f_{i}^{\min }} \\
\mu^{k}=\frac{\sum_{i=1}^{N_{p}} \mu_{i}^{k}}{\sum_{k=1}^{N_{k}} \sum_{i=1}^{N_{p}} \mu_{i}^{k}}
\end{gathered}
$$

In this way the solution with higher $\mu^{k}$ has greater rank.

\section{Conclusion and Future Research Directions}

Meta-heuristic methods need to be examined for performance testing. But there is an important issue here is how it can be argued that the proposed method, this is an effective method. To answer this question it is necessary to use several methods to assess the suitability of the results they achieved an overall result (Arjestan, 2016)

The intense growth in products variety and competitions between firms leads firms to produce more customized product according to customers' requirements. However, this will increase productions cost and products delivery time to customers as well. Therefore in some situations, we need to balance customer requirements with cost and capabilities of production in the supply network. Decoupling point determination is a common practice that is used to address these issues. It Separates a supply chain in two parts and enables firms to use advantages of both lean and agile production system. The first part is 
composed of MTS operations that use standard features and refers to lean production systems and the second part is composed of MTO operations that adjust production to meet specific customer orders. Therefore, efficient determination of decoupling point has found great interest in production concepts. In this paper, we presented a new model to address this problem as an MODM problem. The proposed model here minimizes production cost, delivery time and maximizes customer satisfaction as its objectives and considering operations as MTO or MTS as binary decision variables.

NSGA II is a known algorithm to address MODM problem when decision space is discrete. In this study, we used NSGA II algorithm to find some non-dominated solutions of the problem and present some suggestion to select final solution through Pareto optimal solutions. However, we remember again that choosing between Pareto optimal solutions depends on senior manager decisions and considerations.

Our results of using NSGA II to find Pareto optimal solutions demonstrate good performance of NSGA II to extract Pareto solutions in proposed model that considers determining of decoupling point in a supply network.

In this study, we assume the demand of the product is deterministic and fixed. There is a great area to address decoupling point determination problem with another demand trend such as stochastic demand, demand with fixed batch size, demand reached in fixed interval and so on, that we suggest them for future research. Also we can solve such MODM problem with other methods such as goal programming, $\varepsilon$-constraint, etc., by considering real world application problems.

\section{References}

Aitken, J., (2000) Agility and Leanness - A Successful and Complimentary Partnership in the Lighting Industry. Proceedings LRN 2000 Conference. 1-7.

Agarwal, A., Shankar, R., \& Tiwari, M.K. (2006). Modeling the metrics of lean, agile and leagile supply chain: An ANP-based approach. European J. of Operational Research, 173, 211-225. https://doi.org/10.1016/j.ejor.2004.12.005

Agarwal, A., Shankar, R., \& Tiwari, M.K. (2007). Modeling agility of supply chain. Journal of Industrial Marketing Management, 36, 443-457. https://doi.org/10.1016/j.indmarman.2005.12.004

AL-Fayyaz, A. (2004). Optimization of multi-objective reservoir operation system (Unpublished master's thesis). National University Of Singapore, Singapore, Singapore. Available online at: http://www.scholarbank.nus.edu.sg/handle/10635/14339 
Arjestan, M. (2016). Efficient Optimization of Multi-Objective Redundancy Allocation Problems in Series-Parallel Systems. Decision Science Letters, 6(3), 307-322. https://doi.org/10.5267/j.dsl.2016.11.004

Cao, M., Zhang, Q. (2011). Supply chain collaboration: Impact on collaborative advantage and firm performance. Journal of Operations Management, 29(3), 163-180. https://doi.org/10.1016/j.jom.2010.12.008

Christopher, M., (2000). The Agile Supply Chain: Competing in Volatile Markets. Ind. Mark. Man., 29(1), 37-44. https://doi.org/10.1016/S0019-8501(99)00110-8

Christopher, M., \& Towill, D. (2001). An Integrated Model for the Design of Agile Supply Chaines. International Journal of Physical Distribution \& Logistics Management, 31(4). https://doi.org/10.1108/09600030110394914

Deb, K. (2001). Multi-objective Optimization Using Evolutionary Algorithms. Chichester, U.K.: Wiley.

Deb, K., Pratap, A., Agarwal, S., \& Meyarivan, T.A.M.T. (2002). A fast and elitist multi-objective genetic algorithm: NSGA-II. Evolutionary Computation, IEEE Transactions, 6(2), 182-197. https://doi.org/10.1109/4235.996017

DeGroote, S.E., \& Marx, T.G. (2013). The impact of IT on supply chain agility and firm performance: An empirical investigation. International Journal of Information Management, 33, 909-916. https://doi.org/10.1016/j.ijinfomgt.2013.09.001

Gosling, J., Purvis, L., Naim, M. (2010). Supply chain flexibility as a determinant of supplier selection. International Journal of Production Economics, 128(1,: 11-21.

Krishnamurthy, R., \& Yauch, C.A. (2007). Leagile manufacturing: A proposed corporate infrastructure, Int. J. Of Operations and Production Management, 27(6), 588-604. https://doi.org/10.1108/01443570710750277

Lee, H.L., \& Amaral, J. (2002). Continuous and sustainable improvement through supply chain performance management. Standford Global Supply Chain Management Forum SGSCMF. 1-14.

Naim, M.M., \& Gosling, J. (2011). On leanness, agility and leagile supply chains. International Journal of Production Economics, 131(1), 342-354. http://doi.org/10.1016/j.ijpe.2010.04.045

Nieuwenhuis, P., \& Katsifou, E. (2015). More sustainable automotive production through understanding decoupling points in leagile manufacturing. Journal of Cleaner Production, 95, 232-241.

https://doi.org/10.1016/j.jclepro.2015.02.084

Olhager, J. (2012). The role of decoupling points in value chain management. In Modelling value. 37-47. Physica-Verlag HD. https://doi.org/10.1007/978-3-7908-2747-7_2 
Perez, C., Castro, R., Simons, D., \& Gimenez, G. (2010) Development of lean supply chains: a case study of the Catalan pork sector. Supply Chain Management: An International Journal, 15(1), 55-68. https://doi.org/10.1108/13598541011018120

Srinivas, N., \& Deb, K. (1995). Multi-objective function optimization using non-dominated sorting genetic algorithms. Evolutionary computation, 2(3), 221-248. https://doi.org/10.1162/evco.1994.2.3.221

Sun, X.Y., Ji, P., Sun, L.Y., \& Wang, Y.L. (2008). Positioning multiple decoupling points in a supply network. International Journal of Production Economics, 113(2), 943-956.

https://doi.org/10.1016/j.ijpe.2007.11.012

Tang, D., \& Chen, J. (2009). Identification of postponement point in service delivery process: A description model. Service Systems and Service Management, ICSSSM'09, 6th International Conference on IEEE. 335-339.

Journal of Industrial Engineering and Management, 2017 (www.jiem.org)

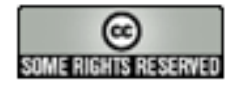

Article's contents are provided on an Attribution-Non Commercial 3.0 Creative commons license. Readers are allowed to copy, distribute and communicate article's contents, provided the author's and Journal of Industrial Engineering and Management's names are included. It must not be used for commercial purposes. To see the complete license contents, please visit http://creativecommons.org/licenses/by-nc/3.0/. 